\title{
Simultaneous determination of azathioprine and its metabolite 6-mercaptopurine in human plasma using solid phase extraction-evaporation and liquid chromatography-positive electrospray tandem mass spectrometry
}

\author{
Mokkaisamy Jegadeesh Raja ${ }^{1}$, Jegadeesh Raja Kavitha ${ }^{1}$, Kothamasu Pavan Kumar ${ }^{2}$, ${ }^{*}$ Thangavel Sivakumar ${ }^{2}$ \\ ${ }^{1}$ Department of Pharmaceutical Analysis, Karpagam University, Coimbatore, TamilNadu, India-641021 \\ ${ }^{2}$ Department of Pharmaceutical Analysis, Nandha College of Pharmacy and Research Institute, Koorapalayam Piruvu, Erode, \\ Tamil Nadu, India-638052
}

\begin{abstract}
A simple, rapid, specific, sensitive and liquid chromatography coupled with tandem mass spectrophotometric method was developed and validated for the estimation of azathioprine and its metabolite 6-mercaptopurine in human plasma by using lamivudine and 6-mercaptopurine D3 as the internal standard. Azathioprine and 6mercaptopurine were extracted from human plasma by solid-phase extraction (SPE)-Evaporation method, using Oasis MCX cartridge for cleaning procedure. The stationary phase was chromatographed on a ZORBAX SB CN, (75X50 mm, $5 \mu$ ) column where as mobile phase constitutes of acetonitrile: $2 \mathrm{mM}$ ammonium acetate $(70: 30 \mathrm{v} / \mathrm{v})$ at a flow rate of $0.800 \mathrm{ml} / \mathrm{min}$. The detection was performed with an Applied Biosystems Sciex API 4000 mass spectrometer by multiple reaction monitoring (MRM). The method validation proofs were carried out as per the USFDA guidelines as described, showing a linearity system $\left(\mathrm{r}^{2}>0.99\right)$ over a range of $2.455 \mathrm{ng} / \mathrm{mL}$ to $106.568 \mathrm{ng} / \mathrm{mL}$ for azathioprine and $1.165 \mathrm{ng} / \mathrm{mL}$ to $101.143 \mathrm{ng} / \mathrm{mL}$ concentrations for 6-mercaptopurine and a recovery shows $99.36 \%$ and $100.44 \%$ for azathioprine and 6-mercaptopurine respectively. The results show that this proposed approach is effective and can be applied to the extraction and analysis of other pharmaceutical compounds.
\end{abstract}

Key Words: Human plasma, multiple reaction monitoring, cartridge, linearity, quality control.

\section{INTRODUCTION}

Azathioprine (6-[(1-Methyl-4-nitro-1H-imidazol-5yl)thio]-1H-purine) (Figure 1) is an immunosuppressant used in organ transplantation and autoimmune disease such as rheumatoid arthritis or inflammatory bowel disease or Crohn's disease (Anstey and Lear, 1988). It is a safe and effective drug used alone in certain autoimmune diseases, or in combination with other immunosuppressants in organ transplantation (Oellerich et al., 1997). Azathioprine acts to inhibit purine synthesis necessary for the proliferation of cells, especially leukocytes and lymphocytes. Azathioprine is a prodrug and more than $80 \%$ of azathioprine is converted to 6-Mercaptopurine (6-MP) (1, 7-Dihydro-

\footnotetext{
*Corresponding Author:

Dr. Thangavel Sivakumar, M.Pharm, PhD

Principal, Department of Pharmaceutical Analysis

Nandha College of Pharmacy and Research Institute

Erode-638052, Tamil Nadu, India

E-mail: sivaecp@yahoo.com

Contact No.: 9842660400
}

6H-purine-6-thione monohydrate) (Figure 2) in the blood by the enzyme glutathione-s-transferase (GST) (Thierry and Roselyne, 1998). Azathioprine and the metabolite 6-MP are moderately bound to serum proteins $(30 \%)$. Azathioprine and 6-MP are structurally very similar, differing only in that azathioprine has a methyl-nitro-imidazolyl group attached to the sulfur atom at the 6-position of the purine ring of 6-MP (Janine and Friedman, 2002, William and Charles, 1975). On the average, $47 \%$ of an orally administered dose of azathioprine is available to the systemic circulation. A number of analytical methods have been used to determine the azathioprine with 6-mercaptopurine. It involves mainly high performance liquid chromatography (Van Os et al., 1996, Fell and Plag, 1979), gas chromatography (Wypior et al., 1982) and very few liquid chromatography tandem mass spectrometry methods (Hofmann et al., 2012, Tibor et al., 2010) have been developed for the quantification in biological samples of plasma (El-Yazigi and Wahab, 
<smiles>Cn1cnc([N+](=O)[O-])c1Sc1ncnc2nc[nH]c12</smiles>

Figure 1 : Structure of Azathioprine.

1992, Albertioni et al., 1995, Maddocks, 1979, Teck and Leslie, 1979) and serum (Sahnoun et al., 1990, Torsten et al., 1996, Tsutsumi et al., 1982). The combination liquid chromatography/mass spectrometry is currently acknowledged as being a powerful means of determining organic molecules from complex biological matrices. The selectivity and sensitivity of LC-MS/MS has allowed for analysis times to be reduced, such that sample preparation time often exceeds the analysis time of samples. Protein precipitation, LLE (Liquid-Liquid Extraction) and SPE (Solid Phase Extraction) are the sample preparation techniques most commonly used to process plasma (Prashant et al., 2011). Protein precipitation has the potential to be significantly less time consuming, while SPE is the technique most amenable and can also be adapted for direct injection. LLE generally provides cleaner extracts than the techniques mentioned previously, as evidenced by reduced matrix effect and less tendency for backpressure build-up in the chromatographic column as more samples are injected.

\section{MATERIAL AND METHOD}

\section{Chemicals and reagents}

Working standards of Azathioprine, Lamivudine, 6Mercaptopurine and 6-Mercaptopurine D3 were procured from Clearsynth Labs and Vivan Life Sciences, Mumbai, India. HPLC grade Acetonitrile was purchased from JT Baker chemicals, Mumbai, India. Ammonium acetate GR grade and Ortho phosphoric acid GR grade were supplied from Merck chemicals, Mumbai, India. The solid phase extraction (SPE) cartridges of Oasis MCX (1 ml, 30 $\mathrm{mg}$ ) were obtained by Waters (Milford, MA, sUSA). All aqueous solutions and buffers were prepared

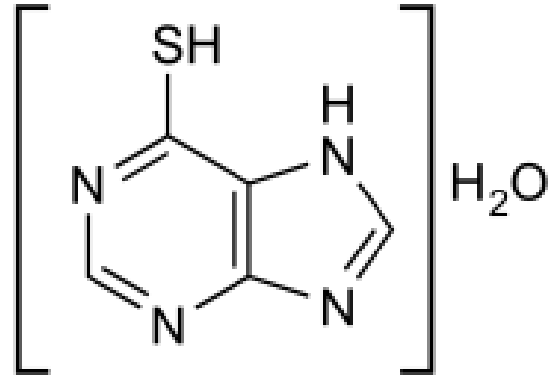

Figure 2: Structure of 6-Mercaptopurine.

using deionized and doubly distilled water (resistivity $>18 \mathrm{MO} \mathrm{cm}$ ) from a Milli-Q-System obtained from In-House were used through out the experiment.

\section{Chromatographic conditions}

The LC system (SHIMADZU) (SILHTP) consists of isocratic pump (LC-20AD Prominence liquid chromatography pump), autosampler (SIL-HTc) and column thermostat. The mobile phase consists of acetonitrile: $2 \mathrm{mM}$ ammonium acetate $(70: 30 \mathrm{v} / \mathrm{v})$ and chromatographic separation was performed at $40^{\circ} \mathrm{C}$ temperature with flow rate $0.800 \mathrm{ml} / \mathrm{min}$ by using ZORBAX SB CN, 75X50 mm, $5 \mu$ column.

\section{Mass Spectrometry conditions}

Mass detection was carried out on a (API 4000, AB SCIEX, USA) equipped with a source of electrospray ionization. The LC-MS/MS detector was operated at unit resolution in Multiple Reaction Monitoring (MRM) mode. The data were acquired using the Analyst 1.5 software. The transitions of molecular ions were found azathioprine- 278.20/142.00, Lamivudine- 230.10/112.20, 6MP- 152.9/119.1 and 6MP D3-156.0/122.0.

Preparation of working standard/quality control (QC) solutions

The stock solution preparation of azathioprine and 6-MP were prepared in basified methanol at concentration of $1000 \mu \mathrm{g} / \mathrm{mL}$ each. The mixed calibration curve of working solutions were prepared from above stock solutions using the diluent of Methanol : Water (50:50 v/v) and ranges from $49.100 \mathrm{ng} / \mathrm{mL}$ to $2131.360 \mathrm{ng} / \mathrm{mL}$ concentrations range for azathioprine and $23.300 \mathrm{ng} / \mathrm{mL}$ to 2022.860 $\mathrm{ng} / \mathrm{mL}$ concentrations range for 6-MP. The quality control samples for azathioprine were prepared at concentrations of $49.640 \mathrm{ng} / \mathrm{mL}$ (LLOQQC), 141.740 $\mathrm{ng} / \mathrm{mL}$ (LQC), 506.240 ng/mL (MQC1), 843.740 
Table 1: Concentration Response Data of Batches: Linearity, Precision and Accuracy of Azathioprine.

\begin{tabular}{lllllllll}
\hline & CC1 & CC2 & CC3 & CC4 & CC5 & CC6 & CC7 & CC8 \\
& $\mathbf{2 . 4 5 5}$ & $\mathbf{4 . 9 1 1}$ & $\mathbf{1 2 . 2 7 7}$ & $\mathbf{2 4 . 5 5 3}$ & $\mathbf{4 0 . 9 2 2}$ & $\mathbf{6 8 . 2 0 4}$ & $\mathbf{8 5 . 2 5 4}$ & $\mathbf{1 0 6 . 5 6 8}$ \\
\hline Reading 1 & 2.530 & 4.394 & 13.483 & 25.164 & 42.582 & 65.858 & 81.975 & 104.821 \\
Reading 2 & 2.400 & 4.923 & 13.899 & 23.118 & 42.931 & 68.117 & 83.513 & 97.905 \\
Reading 3 & 2.425 & 4.915 & 13.545 & 22.237 & 40.902 & 70.470 & 84.988 & 103.657 \\
Mean & 2.4517 & 4.7440 & 13.6423 & 23.5063 & 42.1383 & 68.1483 & 83.4920 & 102.1277 \\
S.D. (+ / -) & 0.06898 & 0.30314 & 0.22443 & 1.50164 & 1.08482 & 2.30616 & 1.50661 & 3.70296 \\
C.V. (\%) & 2.81 & 6.39 & 1.65 & 6.39 & 2.57 & 3.38 & 1.80 & 3.63 \\
\% Nominal & 99.86 & 96.60 & 111.12 & 95.74 & 102.97 & 99.92 & 97.93 & 95.83 \\
\hline
\end{tabular}

Table 2: Concentration Response Data of Batches: Linearity, Precision and Accuracy of 6-MP.

\begin{tabular}{lllllllll}
\hline & \multicolumn{7}{c}{ Nominal Concentration (ng/mL) } \\
\cline { 2 - 9 } & $\mathbf{C C 1}$ & $\mathbf{C C 2}$ & $\mathbf{C C 3}$ & $\mathbf{C C 4}$ & $\mathbf{C C 5}$ & $\mathbf{C C 6}$ & CC7 & CC8 \\
& $\mathbf{1 . 1 6 5}$ & $\mathbf{2 . 3 3}$ & $\mathbf{4 . 6 6 1}$ & $\mathbf{1 1 . 6 5 2}$ & $\mathbf{2 3 . 3 0 3}$ & $\mathbf{3 8 . 8 3 9}$ & $\mathbf{8 0 . 9 1 4}$ & $\mathbf{1 0 1 . 1 4 3}$ \\
Reading 1 & $\mathbf{1 . 1 6}$ & 2.374 & 4.683 & 10.774 & 22.672 & 41.15 & 81.688 & 102.505 \\
Reading 2 & 1.147 & 2.426 & 4.656 & 10.381 & 25.795 & 40.39 & 75.181 & 101.944 \\
Reading 3 & 1.123 & 2.557 & 4.48 & 10.988 & 24.392 & 40.198 & 78.61 & 99.235 \\
Mean & 1.1433 & 2.4523 & 4.6063 & 10.7143 & 24.2863 & 40.5793 & 78.493 & 101.228 \\
S.D. (+ / -) & 0.01877 & 0.0943 & 0.11024 & 0.30787 & 1.56418 & 0.50345 & 3.25508 & 1.74863 \\
C.V. (\%) & 1.64 & 3.85 & 2.39 & 2.87 & 6.44 & 1.24 & 4.15 & 1.73 \\
\% Nominal & 98.14 & 105.25 & 98.83 & 91.95 & 104.22 & 104.48 & 97.01 & 100.08 \\
\hline
\end{tabular}

$\mathrm{ng} / \mathrm{mL}$ (MQC) and $1687.500 \mathrm{ng} / \mathrm{mL}$ (HQC) respectively using the diluents [Methanol : Water (50:50 $\mathrm{v} / \mathrm{v})]$. The quality control samples for 6-MP were prepared at concentrations of $23.740 \mathrm{ng} / \mathrm{mL}$ (LLOQQC), $66.800 \mathrm{ng} / \mathrm{mL}$ (LQC), $477.120 \mathrm{ng} / \mathrm{mL}$ (MQC1), $795.180 \mathrm{ng} / \mathrm{mL}$ (MQC) and $1590.360 \mathrm{ng} / \mathrm{mL}$ (HQC) respectively using diluent [Methanol : Water $(50: 50 \mathrm{v} / \mathrm{v})]$. All solution was stored at $2-8{ }^{\circ} \mathrm{C}$ and was brought to room temperature as when required. The Lamivudine and 6-MP D3 stock solutions (1 $\mathrm{mg} / \mathrm{ml}$ each) were used to prepare IS mixture to achieve concentration $100000.000 \mathrm{ng} / \mathrm{mL}$ for Lamivudine and $320000.000 \mathrm{ng} / \mathrm{mL}$ for 6-Mercaptopurine D3 using diluent [Methanol : Water $(50: 50 \mathrm{v} / \mathrm{v})]$. All solution was stored at $2-8^{\circ} \mathrm{C}$ and was brought to room temperature as when required.

\section{Preparation of calibration curve standards and quality control samples}

The calibration curve standards and quality control samples were prepared by spiking blank plasma with above working solutions at $5 \%$ to preserve the integrity of plasma sample. The mixed calibration curve standards were prepared at concentration of $2.455 \mathrm{ng} / \mathrm{mL}$ to $106.568 \mathrm{ng} / \mathrm{mL}$ for azathioprine and $1.165 \mathrm{ng} / \mathrm{mL}$ to $101.143 \mathrm{ng} / \mathrm{mL}$ for 6-MP. The quality control samples for azathioprine were prepared at concentrations of $2.482 \mathrm{ng} / \mathrm{mL}$ (LLOQQC), 7.087 $\mathrm{ng} / \mathrm{mL}$ (LQC), $25.312 \mathrm{ng} / \mathrm{mL}$ (MQC1), $42.187 \mathrm{ng} / \mathrm{mL}$ (MQC) and $84.375 \mathrm{ng} / \mathrm{mL}$ (HQC) respectively using the diluent [Methanol : Water $(50: 50 \mathrm{v} / \mathrm{v})]$. The quality control samples for 6-MP were prepared at concentrations of $1.187 \mathrm{ng} / \mathrm{mL}$ (LLOQQC), 3.340 $\mathrm{ng} / \mathrm{mL}$ (LQC), $23.856 \mathrm{ng} / \mathrm{mL}$ (MQC1), $39.759 \mathrm{ng} / \mathrm{mL}$ (MQC) and $79.518 \mathrm{ng} / \mathrm{mL}$ (HQC) respectively using diluent [Methanol : Water $(50: 50 \mathrm{v} / \mathrm{v})]$. All aliquots of spiked plasma were transferred to RIA tube and stored at below $-70 \pm 5^{\circ} \mathrm{C}$.

\section{Sample Preparation and Extraction}

Aliquot $500 \mu \mathrm{L}$ of spiked Plasma sample in RIA tube, add $50 \mu \mathrm{L}$ (6-Mercaptopurine Labeled (6MP-D3) + Lamivudine), internal standard solution (Except calibration blank) and vortex it for 10 seconds. Add $500 \mu \mathrm{L}$ of $2 \%$ O-Phosphoric acid and vortex for 30 seconds. Condition Oasis MCX cartridges with 1.0 $\mathrm{mL}$ of methanol and equilibrate with $1.0 \mathrm{~mL}$ of $2 \%$ O-Phosphoric acid, load the sample in SPE manifold and wash SPE cartridges with $1.0 \mathrm{~mL}$ of $2 \% \mathrm{O}$ Phosphoric acid and1.0 mL of acidified Methanol (pH: 2.3). Elute the cartridges with $2.0 \mathrm{~mL}$ of $5 \%$ ammonia in methanol and evaporate the sample at 
Table 3: Intra-Run Precision and Accuracy (PA) (Batch 01, 02 and 03) of Azathioprine.

\begin{tabular}{lccccc}
\hline $\begin{array}{l}\text { Nominal } \\
\text { Concentration } \\
\text { (ng/mL) }\end{array}$ & LLOQ QC & LQC & MQC1 & MQC & HQC \\
\cline { 2 - 6 } & 2.482 & 7.087 & 25.312 & 42.187 & 84.375 \\
\hline PA BATCH-01 & & & & & \\
\hline Mean & 2.4077 & 6.8788 & 26.3325 & 42.9318 & 88.0992 \\
S.D. (+ / -) & 0.10763 & 0.83238 & 1.95318 & 2.70443 & 10.54774 \\
C.V. (\%) & 4.47 & 12.1 & 7.42 & 6.3 & 11.97 \\
\% Nominal & 97.01 & 97.06 & 104.03 & 101.77 & 104.41 \\
\hline PA BATCH-02 & & & & & \\
\hline Mean & 2.3188 & 6.8653 & 26.7838 & 42.1197 & 87.1977 \\
S.D. (+ / -) & 0.09098 & 0.7238 & 2.64589 & 1.78127 & 11.72285 \\
C.V. (\%) & 3.92 & 10.54 & 9.88 & 4.23 & 13.44 \\
\% Nominal & 93.43 & 96.87 & 105.81 & 99.84 & 103.35 \\
\hline PA BATCH-03 & \multicolumn{5}{c}{} \\
\hline Mean & 2.4218 & 6.2945 & 24.4197 & 40.0023 & 86.2287 \\
S.D. (+ / -) & 0.10946 & 0.40974 & 1.37439 & 2.75257 & 10.48678 \\
C.V. (\%) & 4.52 & 6.51 & 5.63 & 6.88 & 12.16 \\
\% Nominal & 97.58 & 88.82 & 96.47 & 94.82 & 102.2 \\
\hline & & & & \\
\hline
\end{tabular}

$50^{\circ} \mathrm{C}$ under nitrogen gas at 15 psi. Reconstitute the dried residue with $200 \mu \mathrm{L}$ of Mobile phase [(acetonitrile: $2 \mathrm{mM}$ ammonium Acetate $(70: 30 \mathrm{v} / \mathrm{v})]$ and inject $20 \mu \mathrm{L}$ of volume into LC-MS/MS.

\section{RESULTS AND DISCUSSION}

The method here in presented is specific SPEEvaporation protocol allowed a rapid method for the simultaneous extraction of azathioprine and 6MP to be developed, since a large number of samples can be determined daily by using this approach (Dervieux and Boulieu, 1998, Kato et al., 1991). As for the extraction itself, the selected method proved to be very simple and reproducible. The Solid Phase Extraction (SPE) procedure with Oasis MCX cartridges provided cleaner samples and good recovery (Angela et al., 2008). The addition of $2 \%$ O-Phosphoric acid enhances the analyte interest retention other than plasma elements in SPE cartridges that influences the matrix effect (Matrinez et al., 2003, Petrovic et al., 2002). The addition of $2 \%$ O-Phosphoric acid and acidified methanol ( $\mathrm{pH}-2.3)$ washing solution at washing step, decreased the presence of plasma elements upto $>80 \%$, when compared with the use of pure water washing twice (Miao et al., 2002, Hilton and Thomas, 2003). However, even with this improvement, the final evaporation method for eluent aids further cleaner sample and improved sensitivity. The co-elution of plasma elements produced (despite the MRM)
Table 4: Intra-Run Precision and Accuracy (PA Batch-01, 02 and 03) of 6-Mercaptopurine.

\begin{tabular}{lccccc}
\hline $\begin{array}{l}\text { Nominal } \\
\text { Concentration } \\
\text { (ng/mL) }\end{array}$ & LLOQ QC & LQC & MQC1 & MQC & HQC \\
\hline PA BATCH-01 & 1.187 & 3.34 & 23.856 & 39.759 & 79.518 \\
\hline Mean & 1.2185 & 3.2678 & 22.9697 & 41.5532 & 86.5722 \\
S.D. (+ / ) & 0.07725 & 0.13571 & 0.71807 & 1.13516 & 3.27848 \\
C.V. (\%) & 6.34 & 4.15 & 3.13 & 2.73 & 3.79 \\
\% Nominal & 102.65 & 97.84 & 96.28 & 104.51 & 108.87 \\
\hline PA BATCH-02 & & & & & \\
\hline Mean & 1.1717 & 3.3932 & 22.6685 & 38.9742 & 88.0208 \\
S.D. (+ / -) & 0.05269 & 0.14143 & 0.39698 & 2.16538 & 2.27225 \\
C.V. (\%) & 4.5 & 4.17 & 1.75 & 5.56 & 2.58 \\
\% Nominal & 98.71 & 101.59 & 95.02 & 98.03 & 110.69 \\
\hline PA BATCH-03 & \multicolumn{5}{c}{} \\
\hline Mean & 1.2053 & 3.4698 & 23.5697 & 41.2802 & 87.5738 \\
S.D. (+ / -) & 0.04476 & 0.23348 & 0.73211 & 2.23062 & 4.16565 \\
C.V. (\%) & 3.71 & 6.73 & 3.11 & 5.4 & 4.76 \\
\% Nominal & 101.54 & 103.89 & 98.8 & 103.83 & 110.13 \\
\hline & & & & \\
\hline
\end{tabular}

unexpected peaks when short $\mathrm{C}_{8}$ and $\mathrm{C}_{18}$ columns (50 mm) were applied. The use of ZORBAX SB CN column, 75X50 mm, $5 \mu$ increased the run time (3.0 min) but decreased the intensities of the peaks attributed to plasma elements. Furthermore, these peaks didn't appear in the respective retention times of azathioprine and 6-MP (Figure. 03, 04, 06 and 07). The $\mathrm{S} / \mathrm{N}$ ratio was found to be $>5$ for azathioprine and 6-MP in the lower standard sample, which was set to be the LOQ, Since these peaks were determined using normal blank plasma, further experiments with hemolyzed and lipemic blank plasma were also performed, but the yield chromatograms for these did not exhibit any real differences from those for normal blank plasma (Figure. 05 \& 08). Judging from our experience, there are very few hemolyzed and lipemic samples present among the hundreds obtained from a bioequivalence study. Therefore, the samples obtained from such studies are expected to show the same behavior with the spiked plasma samples produced during the pre-study validation. After the completion of the pre-study validation, the ESI source was quite clean, which is of great significance for SPE extraction protocols and evaporation. Therefore, it might be necessary to clean the source in the middle of a bioequivalence study (usually $>1000$ samples), especially if the signal intensity has decreased. We intend to provide studies dealing with the interference obtained from plasma elements in ESI when following an SPE-Evaporation 
Table 5: Inter-Run Precision and Accuracy of Azathioprine \& 6-Mercaptopurine.

\begin{tabular}{llllll}
\hline & \multicolumn{5}{c}{ Azathioprine } \\
& LLOQ QC & LQC & MQC 1 & MQC & HQC \\
\cline { 2 - 6 } Concentration (ng/mL) & 2.482 & 7.087 & 25.312 & 42.187 & 84.375 \\
Mean & 2.3828 & 6.6796 & 25.8453 & 41.6846 & 87.1752 \\
S.D. (+ / ) & 0.10754 & 0.69697 & 2.20196 & 2.63201 & 10.30067 \\
C.V. (\%) & 4.51 & 10.43 & 8.52 & 6.31 & 11.82 \\
\% Nominal & 96 & 94.25 & 102.11 & 98.81 & 103.32 \\
\hline & & & 6-Mercaptopurine & HQC \\
Concentration (ng/mL) & LLOQ QC & LQC & MQC 1 & MQC & 79.518 \\
& 1.187 & 3.34 & 23.856 & 39.759 & 87.3889 \\
Mean & 1.1985 & 3.3769 & 23.0693 & 40.6025 & 3.18936 \\
S.D. (+ / ) & 0.05977 & 0.18621 & 0.71008 & 2.15369 & 3.65 \\
C.V. $(\%)$ & 4.99 & 5.51 & 3.08 & 5.3 & 103.57 \\
\% Nominal & 100.97 & 47.65 & 91.14 & 96.24 & \\
\hline
\end{tabular}

Table 6: Stability data of Azathioprine and 6-Mercaptopurine.

\begin{tabular}{|c|c|c|c|c|c|c|}
\hline \multirow[t]{2}{*}{ Stability } & \multicolumn{3}{|c|}{ Azathioprine } & \multicolumn{3}{|c|}{ 6-Mercaptopurine } \\
\hline & $\begin{array}{c}\text { Nominal Concentration } \\
\left(\text { ng mL } L^{-1}\right)\end{array}$ & $\begin{array}{c}\% \\
\text { Bias } \\
\end{array}$ & $\begin{array}{l}\% \mathrm{CV} \\
(\mathrm{n}=6)\end{array}$ & $\begin{array}{c}\text { Nominal Concentration } \\
(\mathrm{ng} \mathrm{mL}-1)\end{array}$ & $\begin{array}{c}\% \\
\text { Bias } \\
\end{array}$ & $\begin{array}{l}\% \mathrm{CV} \\
(\mathrm{n}=6)\end{array}$ \\
\hline \multirow[t]{2}{*}{ Bench Top } & LQC-7.087 & -4.14 & 5.82 & LQC-3.340 & 4.13 & 6.26 \\
\hline & HQC-84.375 & 3.32 & 8.38 & HQC-79.518 & 5.34 & 2.84 \\
\hline \multirow[t]{2}{*}{ Freeze Thaw } & LQC-7.087 & 1.35 & 8.06 & LQC-3.340 & -0.68 & 3.2 \\
\hline & HQC-84.375 & -5.27 & 7.94 & HQC-79.518 & 1.73 & 6.69 \\
\hline \multirow[t]{2}{*}{ Long Term Stability in Matrix } & LQC-7.087 & 6.69 & 11.12 & LQC-3.340 & -1.39 & 4.23 \\
\hline & HQC-84.375 & 8.34 & 5.5 & HQC-79.518 & 0.5 & 5.6 \\
\hline
\end{tabular}

protocol in an upcoming report. The retention times of all compounds and the column backpressure remained practically constant by the end of prestudy validation.

\section{Method Validation}

The complete validation was performed according to the guidelines of US Food and Drug Administration (USFDA) on bioanalytical method validation (Guidance for Industry, 2003, Guidance for Bioavailability and Bioequivalence Studies, 2005, Guidance for Industry, 2001, Chow and Liu, 1999).

\section{Linearity}

Linearity was used to confine the performance of the method. A linear least squares regression with a three calibration curves were prepared using eight non-zero standards ranging from $2.455 \mathrm{ng} / \mathrm{mL}$ to $106.568 \mathrm{ng} / \mathrm{mL}$ for azathioprine and $1.165 \mathrm{ng} / \mathrm{mL}$ to $101.143 \mathrm{ng} / \mathrm{mL}$ for 6-MP for each analytical run. Peak area ratios of each drug to IS were used for regression analysis. A linear regression model $(y=m x+c)$ was evaluated, using $1 / X^{2}$ as weighting factor, where $X$ is the concentration of each drug and $y$ corresponds to the areas ratio. The regression coefficients $\left(\mathrm{r}^{2}\right)$ for the three runs were greater than 0.98 for azathioprine and 6-MP. The standard curves obtained for the two molecules are presented in Table 1 and 2, respectively. Consequently, SPEEvaporation procedure applied in this method was able to produce satisfactory concentration data for azathioprine and 6-MP standard samples.

\section{Sensitivity}

The limit of detection (LOD) and the limit of quantification (LOQ) were performed by measuring the analytical background response. The individual standard curve data from three runs met all of the preset criteria: i) $<20 \%$ deviation from the nominal concentration at the limit of quantification (LOQ), which was defined as the lowest standard, ii) $<15 \%$ deviation of standards from their back calculated concentration, other than LOQ from nominal concentrations, iii) at least six out of eight nonzero 


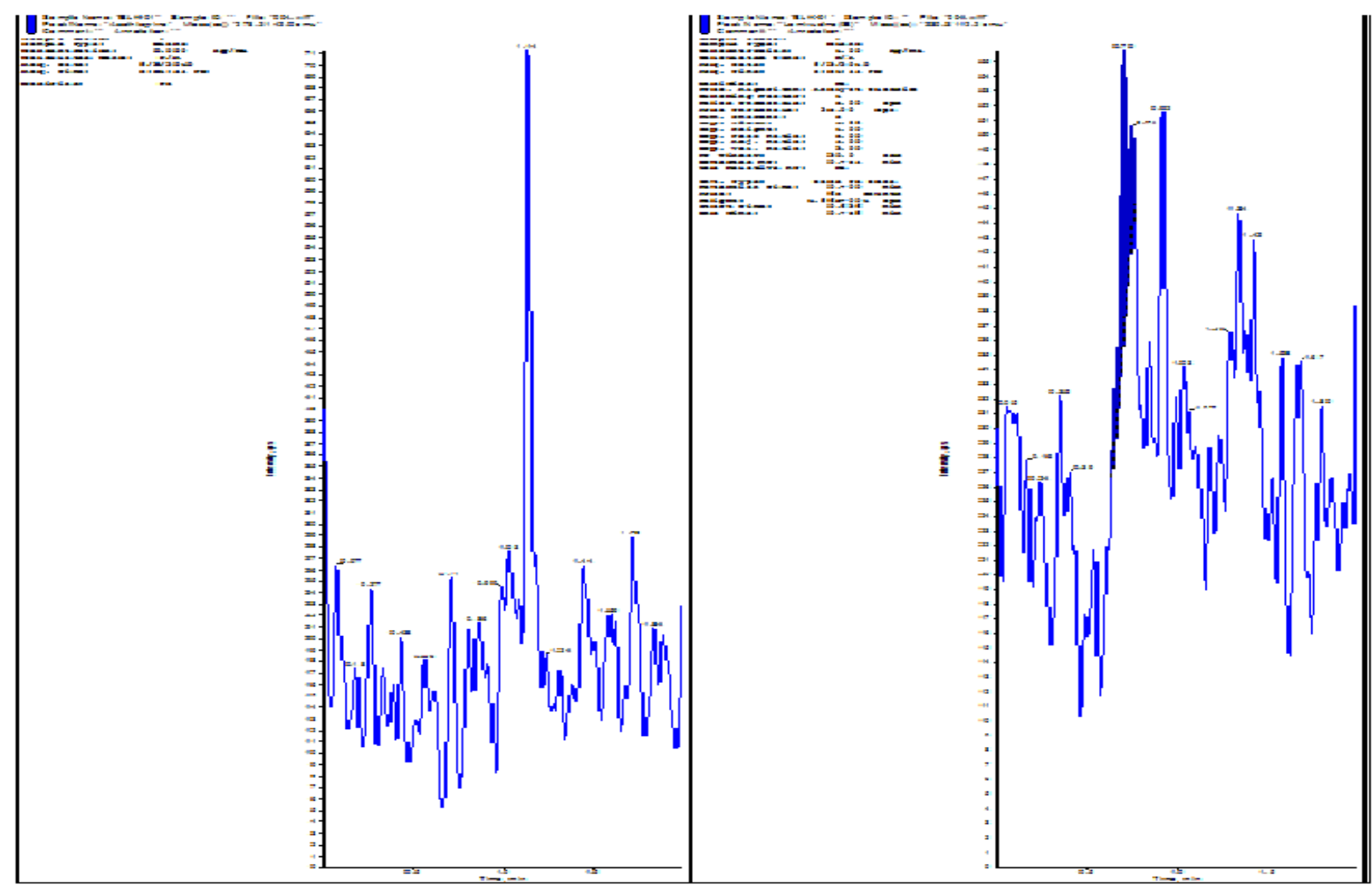

Figure 3: Blank of Azathioprine extracted from plasma.

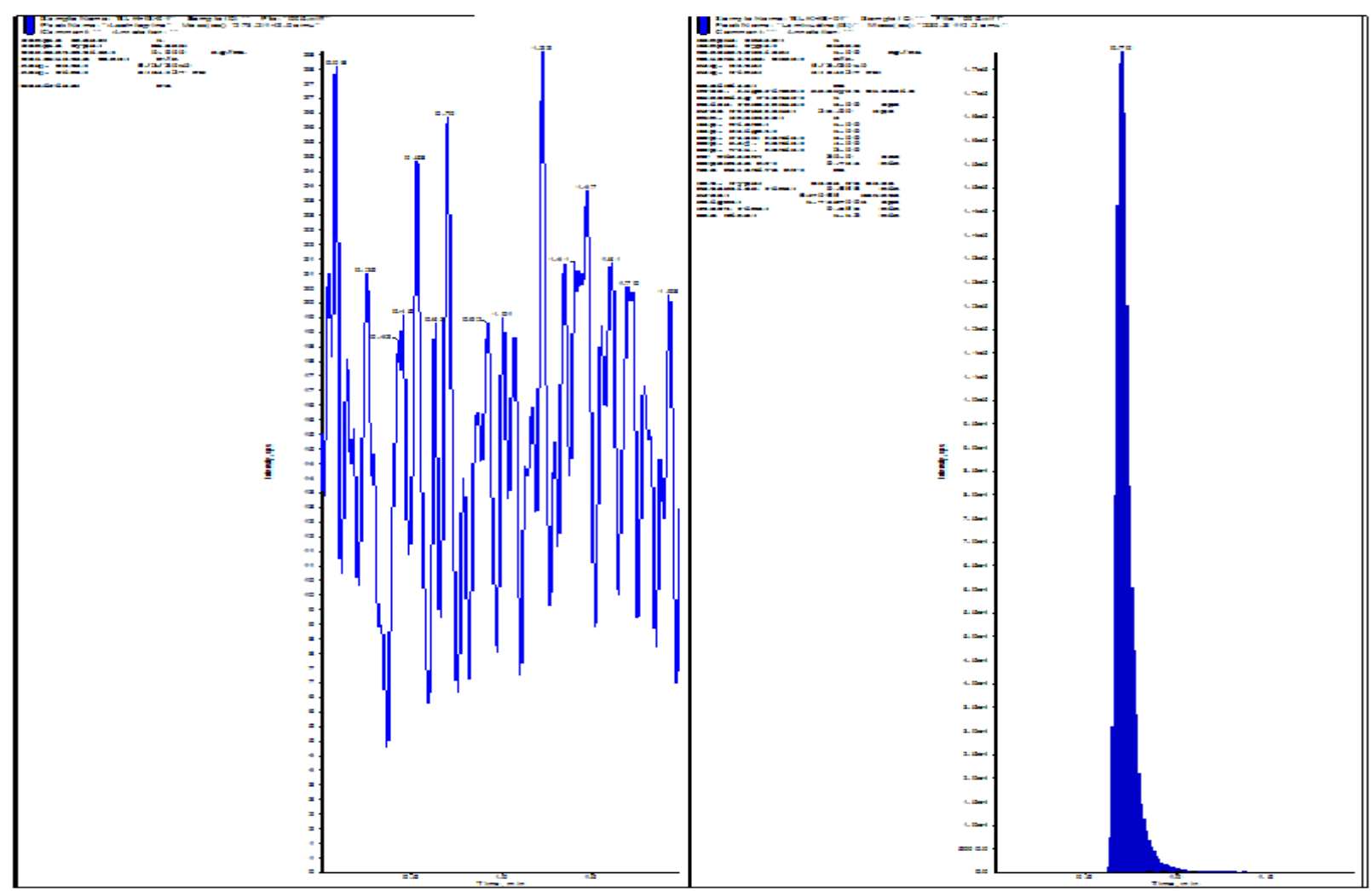

Figure 4: Chromatogram of Azathioprine with its internal standard. 


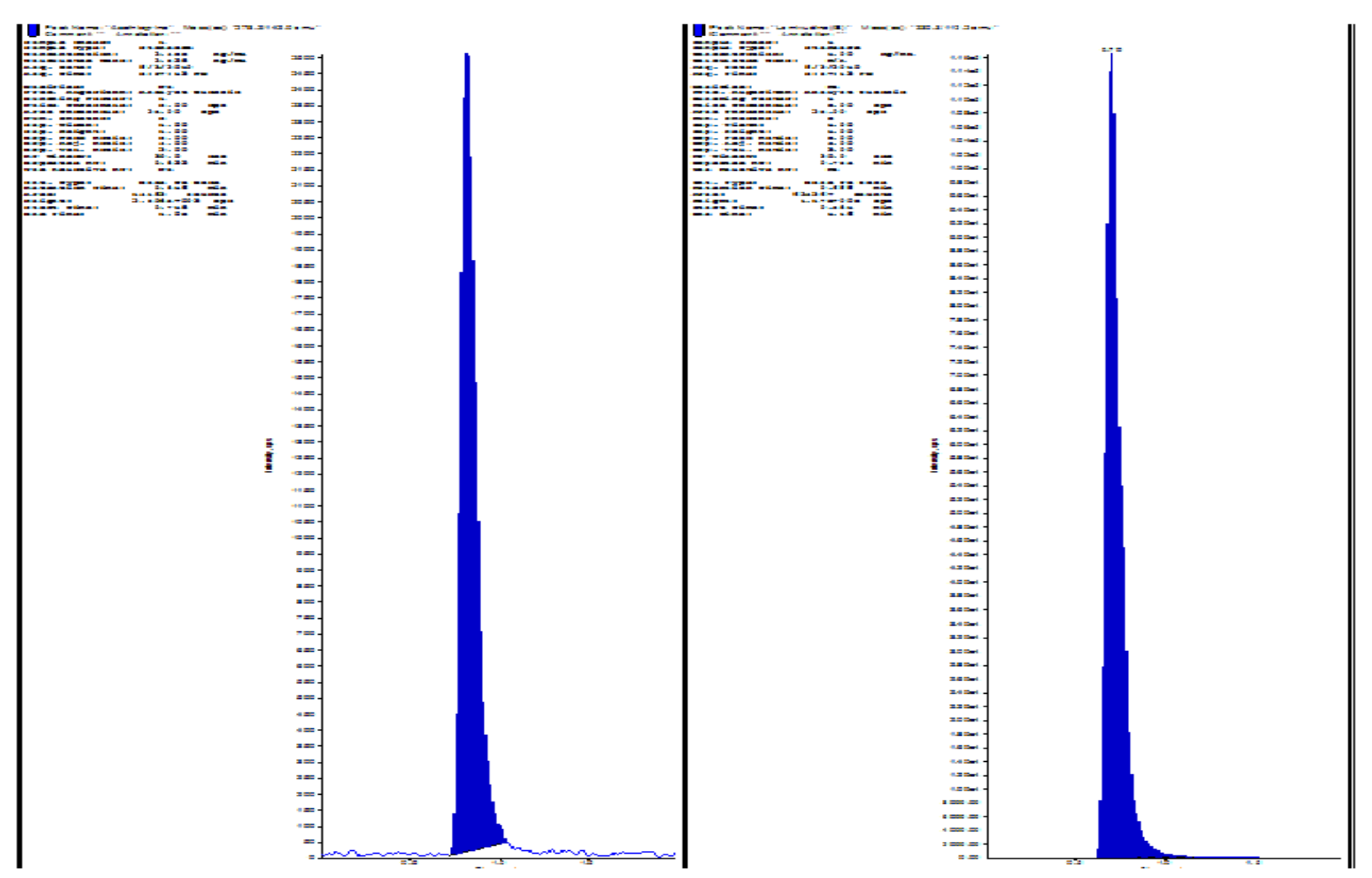

Figure 5: LLOQ Chromatogram of Azathioprine.

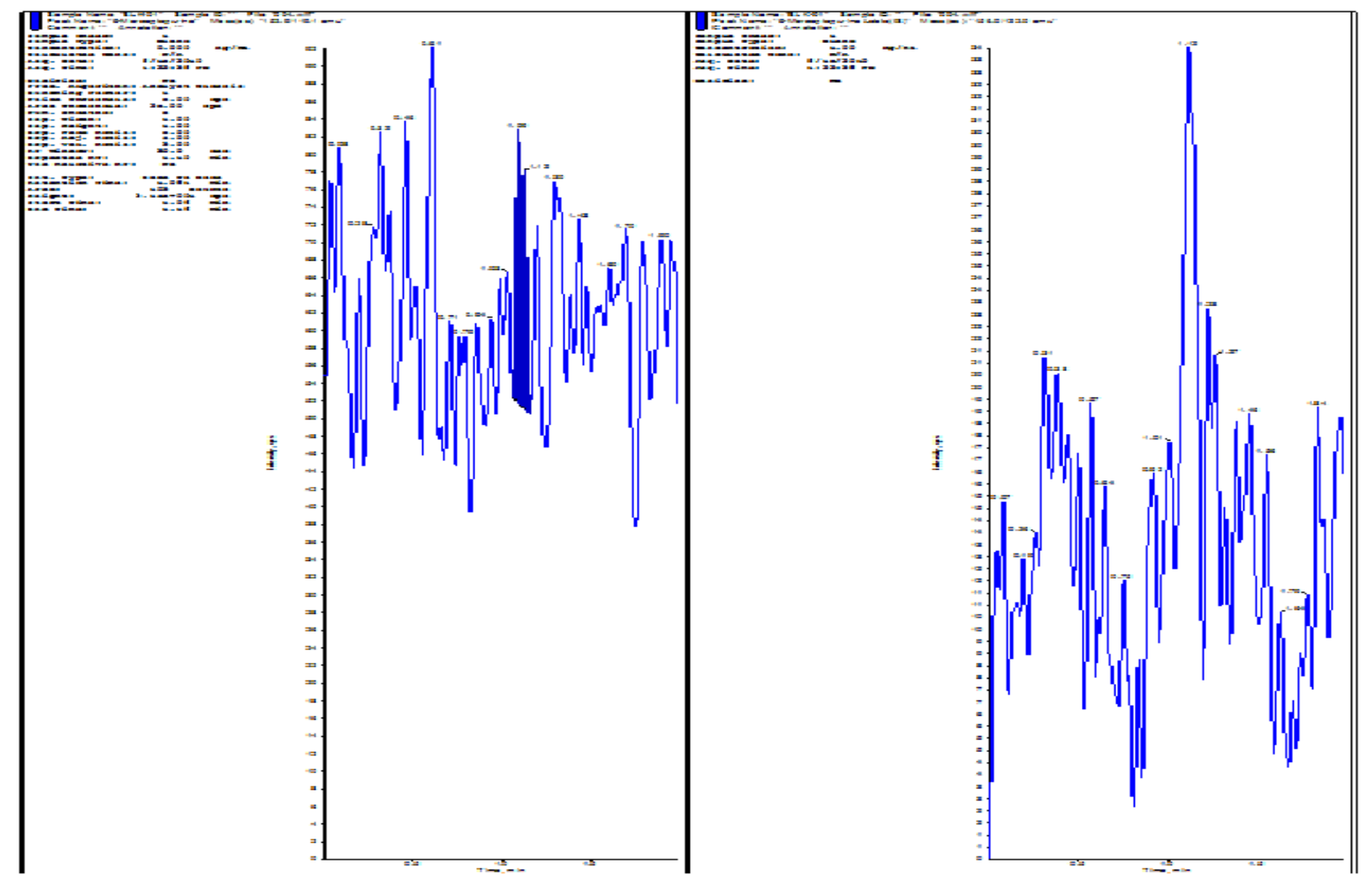

Figure 6: Blank of 6-Mercaptopurine extracted from plasma. 


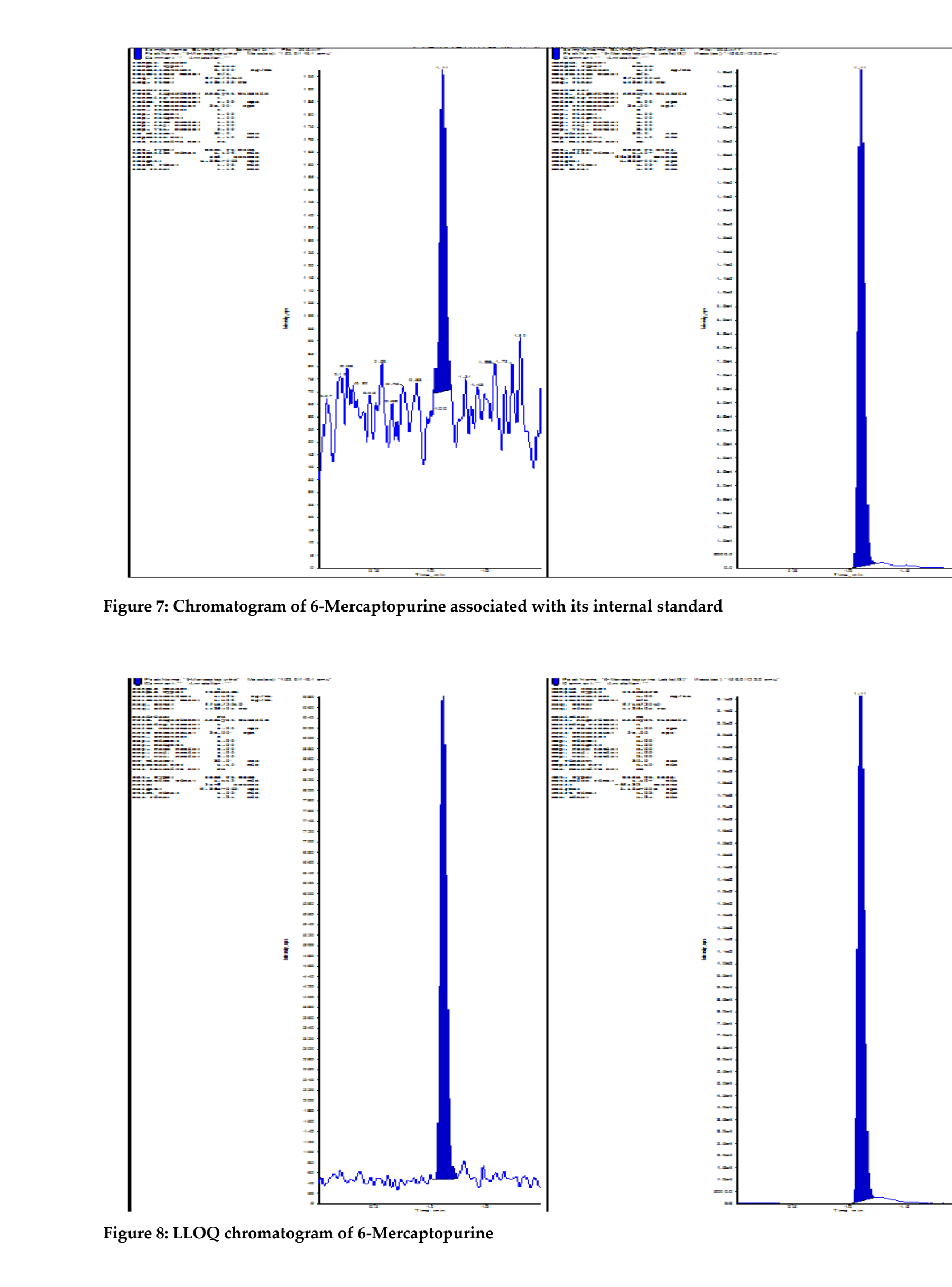


standards of each nominal concentration meeting the above criteria, including the LOQ and the calibration standard at the highest concentration.

\section{Accuracy and precision}

The precision and accuracy were also assessed by analyzing method validation samples over three runs. The percentage accuracy was determined by calculating the deviations of the predicted concentrations from their nominal values. The intra-assay precision was assessed by analyzing six replicates at each QC level, while the inter-assay precision was determined over three runs conducted on two days by analyzing 30 samples. Data for both types of accuracy and precision (expressed as $\mathrm{CV} \%$ ) are presented in Tables 3, 4 and 5 azathioprine and 6MP respectively. These results, as well as the respective values for the percentage accuracy were within the acceptance criteria.

\section{Stability studies}

The stability quality control plasma samples LQC$7.087 \mathrm{ng} / \mathrm{mL}$ and HQC- $84.375 \mathrm{ng} / \mathrm{mL}$ for azathioprine and LQC-3.340 ng/mL and HQC-79.518 ng/mL for 6MP (Table 6). To evaluate the freeze-thaw stability, a freeze-and-thaw cycle was defined as the storage of LQC and HQC samples at $-80^{\circ} \mathrm{C}$, followed by thawing at room temperature. Samples were analyzed after the fifth cycle, along with fresh reference samples of the same concentration. Back-calculated concentrations of fifth freeze-thaw cycles versus fresh were within the acceptance limit ( $<10 \%$ variation).

To evaluate the Bench top stability, six aliquots of LQC and HQC were maintained at room temperatures for $23 \mathrm{Hrs} 23 \mathrm{Min}$ without processing (which exceeds the time that samples normally remain at room temperature). After a stipulated period of storage over bench, stability samples were processed and analyzed against fresh CC and fresh QC.

To check long-term stability, aliquots of the two sample types were initially frozen at $-70^{\circ} \mathrm{C}$ for 30 days, and then thawed and analyzed. The 30 day period is more than adequate for the analysis of samples from a bioequivalence study, since the current method allows the measurement of more number of samples per day. All of the molecules were stable $(<10 \%$ variation) under these conditions. Stock solution stability was estimated by comparing
Table 7: Summary data of Recovery studies.

\begin{tabular}{lll}
\hline & AZA (\%) & 6-MP (\%) \\
\hline LQC & 99.32 & 100.63 \\
MQC1 & 99.67 & 99.48 \\
MQC & 100.23 & 100.36 \\
HQC & 98.22 & 101.32 \\
Avg & 99.36 & 100.44 \\
\hline
\end{tabular}

fresh and old dilutions in mobile phase of these solutions (stored at $4^{\circ} \mathrm{C}$ ). The measurements proved that the concentrations of azathioprine and 6-MP in stock solution remained intact (variation $<5 \%$ ).

Autosampler stability was another part of the method validation that was tested. This was assessed by comparing QC samples included at the beginning, at half-way and upon completion of each of the three analytical runs. The stabilities of all molecules in the autosampler $\left(5^{\circ} \mathrm{C}\right)$ were acceptable.

\section{Recovery Studies}

The recovery of the proposed method, were spiked with different concentrations of azathioprine and 6MP. The recovery was obtained by performing the mean response of each concentration and dividing with the extracted sample mean by the unextracted (spiked blank plasma extract) sample mean of the actual concentration (Table 7). The difference between the unextracted samples, spiked plasma residues and the extracted sample was done in order to minimize the matrix effects, giving a true recovery. The recoveries observed for azathioprine and mercaptopurine was $99.36 \%$ and $6-\mathrm{MP}$ was $100.44 \%$.

\section{CONCLUSION}

A SPE-Evaporation protocol described above was developed for the simultaneous quantification of Azathioprine and 6-Mercaptopurine in human plasma. Azathioprine is a prodrug, which convert into active metabolite 6-Mercaptopurine in the blood after it has been administered. The current method includes, for the first time, a single sample preparation procedure and a rapid LC-MS/MS protocol. Therefore, more number of samples can be analyzed daily, while only small quantities of plasma and solvent are consumed. The method developed here was validated over the concentration $2.455 \mathrm{ng} / \mathrm{mL}$ to $106.568 \mathrm{ng} / \mathrm{mL}$ for azathioprine 
and $1.165 \mathrm{n} \mathrm{g} / \mathrm{mL}$ to $101.143 \mathrm{ng} / \mathrm{mL}$ for 6-MP. These ranges are suitable for measuring these drugs in plasma samples obtained for a pharmacokinetic or bioequivalence study. The method possessed excellent precision and accuracy and proved to be reliable. It is expected that this approach can be applied to the extraction and analysis of other pharmaceutical compounds with different physicochemical properties from biological samples.

\section{ACKNOWLEDGEMENT}

We gratefully thank to the Chairman, V. Shanmugan and S. Nandha Kumar Pradeep, Secretary, Nandha College of Pharmacy and Research Institute, Erode, Tamilnadu, India for their support.

\section{REFERENCES}

Albertioni, F., Pettersson, B., Ohlman, S., Peterson, C. (1995). Analysis of Azathioprine and 6-Mercaptopurine in Plasma in Renal Transplant Recipients after Administration with Oral Azathioprine. Journal of Liquid Chromatography and Related Technologies, Volume 18, Issue 20, Pages 39914005. [DOI]

Angela, L.B., Mitch, S.K., James, M.L. (2008). Analysis of Ecologically Relevant Pharmaceuticals in Wastewater and Surface Water Using Selective Solid-Phase Extraction and UPLC-MS/MS. Analytical Chemistry, Volume 80, Issue 13, Pages 5021-5030. [DOI] PMid:18498179

Anstey, A., Lear, J.T. (1998). Azathioprine: clinical pharmacology and current indications in autoimmune disorders. BioDrugs, Volume 9, Issue 1, Pages 33-47. [DOI]

Chow, C.S., Liu, J.P. (1999). Design and Analysis of Bioavailability and Bioequivalence Studies. (2nd ed., pp. 1-600). United States, CRC Press.

Dervieux, T., Boulieu, R. (1998). Simultaneous determination of 6-thioguanine and methyl 6-mercaptopurine nucleotides of azathioprine in red blood cells by HPLC. Clinical Chemistry, Volume 44, Issue 3, Pages 551-555. PMid:9510860

El-Yazigi, A., Wahab, F.A. (1992). Expedient liquid chromatographic analysis of azathioprine in plasma by use of silica solid phase extraction. Therepeutic Drug Monitoring, Volume 14, Issue 4, Pages 312-316. [DOI]

Fell, F., Plag, S.M. (1979). Stability-indicating assay for azathioprine and 6-mercaptopurine by reversed-phase high-performance liquid chromatography. Journal of chromatography A, Volume 186, Issue 30, Pages 691-704. [DOI]
Guidance for Bioavailability and Bioequivalence Studies for Chemical Drug Products. China: State of Food and Drug Administration, March 2005, Pages 1-33.

Guidance for Industry: Bioanalytical Method Validation. US Dept of Health and Human Services, Food and Drug Administration (FDA), Center for Drug Evaluation and Research (CDER), May 2001, Pages 1-45.

Guidance for Industry: Bioavailability and Bioequivalence Studies for Orally Administered Drug Products-General Considerations.US Dept of Health and Human Services, Food and Drug Administration (FDA), Center for Drug Evaluation and Research (CDER), March 2003, Pages 1-23.

Hilton, M.J., Thomas, K.V. (2003). Determination of selected human pharmaceutical compounds in effluent and surface water samples by high-performance liquid chromatography-electrospray tandem mass spectrometry. Journal of Chromatography A, Volume 1015, Issue 1-2, Pages 129-141. [DOI]

Hofmann, U., Heinkele, G., Angelberger, S., Schaeffeler, E., Lichtenberger, C., Jaeger, S., et al. (2012) Simultaneous quantification of eleven thiopurine nucleotides by liquid chromatography-tandem mass spectrometry. Analytical Chemistry, Volume 84, Issue 3, Pages 1294-1301. [DOI]

Janine, E.P., Friedman, J.M. (2002). Teratogen update: Azathioprine and 6-mercaptopurine. Tetralogy, Volume 65, Issue 5, Pages 240-261. [DOI]

Kato, Y., Matsushita, T., Yokoyama, T., Mohri, K (1991). Determination of 6-mercaptopurine in acute lymphoblastic leukemia patients plasma by high performance liquid chromatography. Therapeutic Drug Monitoring, Volume 13, Issue 3, Pages 220-225. [DOI]

Maddocks, J.L. (1979). Assay of azathioprine, 6mercaptopurine and a novel thiopurine metabolite in human plasma. British Journal of Clinical Pharmacology, Volume 8, Issue 3, Pages 273-278. [DOI]

Martinez, M., Gans, O., Weber, H., Scharf, E. in: H.Fr. Schroder (Ed.), Ecohazard (2003). Proceedings of the 4th IWA Specialized Conference on Assessment and Control of Hazardous Substances in Water.

Miao, X.S., Koenig, B.G., Metcalfe, C.D. (2002). Analysis of acidic drugs in the effluents of sewage treatment plants using liquid chromatography-electrospray ionization tandem mass spectrometry. Journal of Chromatography A, Volume 95, Issue 2(1-2), Pages 139-147. [DOI]

Oellerich, M., Schütz, E., Armstrong, V.W. (1997). Monitoring of cyclosporin and azathioprine in organ transplantation. Drug Metabolism and Drug Interactions, Volume 14, Issue 1, Pages 17-31. [DOI]

Petrovic, M., Eljarrat, E., L'opez de Alda, M.J., Barcel'o, D. (2002). Recent advances in the mass spectrometry analysis related to endocrine disrupting compounds in aquatic environmental samples. Journal of Chromatography A, Volume 974, Issue 1-2, Pages 23-51. [DOI] 
Prashant, L.K., Gantala, V., Jignesh, K., Ravi, S. (2011). Recent advances in sample preparation techniques for effective bioanalytical methods. Biomedical Chromatography, Volume 25, Issue (1-2), Pages 199-217. [DOI]

Sahnoun, Z., Serre, D.F., Lang, J., Faucon, G., Gavend, M. (1990). Determination of 6-mercaptopurine and its metabolites in plasma or serum by high performance liquid chromatography. Biomedical Chromatography, Volume 4, Issue 4, Pages 144-147. [DOI] PMid:2207374

Teck, L.D., Leslie, Z.B. (1979). Determination of 6mercaptopurine and azathioprine in plasma by highperformance liquid chromatography. Journal of Chromatography B: Biomedical Sciences and Applications, Volume 163, Issue 3, Pages 281-288.

Thierry, D., Roselyne, B. (1998). Simultaneous determination of 6-thioguanine and methyl 6-mercaptopurine nucleotides of azathioprine in red blood cells by HPLC. Clinical Chemistry, Volume 44, Issue 3, Pages 551-555. PMID: 9510860

Tibor, B., Marek, Z., Jiri, V., Percy, N., Marie, C.G., Petre, T., et al. (2010). Tandem mass spectrometry identification and LC-MS quantification of intact cytokinin nucleotides in K562 human leukemia cells. Analytical and Bioanalytical Chemistry, Volume 398, Issue 5, Pages 2071-2080. [DOI]
Torsten, B., Hartmut, M., Hans, H.W. (1996). Highperformance liquid chromatographic assay for the measurement of azathioprine in human serum samples. Journal of chromatography B: Biomedical sciences and Applications, Volume 675, Issue 26, Pages 287-294. [DOI]

Tsutsumi, K., Otsuki, Y., Kinoshita, T. (1982). Simultaneous determination of azathioprine and 6-mercaptopurine in serum by reversed-phase high-performance liquid chromatography. Journal of Chromatography, Volume 231, Issue 2, Pages 393-399. [DOI]

Van Os, E.C., McKinney, J.A., Zins, B.J., Mays, D.C., Schriver, Z.H., Sandborn, W.J., Lipsky, J.J. (1996). Simultaneous determination of azathioprine and 6-mercaptopurine by high-performance liquid chromatography. Journal of Chromatography B: Biomedical Sciences and Applications, Volume 679, Issue 1-2, Pages 147-154. [DOI]

William, J.C., Charles, E.B. (1975). Crystal structures of azathioprine dihydrate and 6-methylmercaptopurine trihydrate. Journal of Pharmaceutical Sciences, Volume 64, Issue 2, Pages 221-225. [DOI]

Wypior, H.J., Schilling, A., Von Meyer, L., Land, W. (1982). A gas chromatographic determination of 6-mercaptopurine in the serum of immunosuppressed transplantation patients. Research in Experimental Medicine (Berl), Volume 181, Issue 1, Pages 19-25. [DOI] 